\title{
CARTOGRAFIA DA EDUCAÇÃO SUPERIOR NO MUNICÍPIO DE NITERÓI ${ }^{1}$
}

\author{
Maria de Fátima de Paula*
}

Recebido em: 15/10/07

Avaliado em: 20/01/2008

*Professora da Faculdade de Educação e do Programa de Pós-Graduação em Educação da Universidade Federal Fluminense (UFF) e Coordenadora do Núcleo de Estudos e Pesquisas em Educação Superior da UFF. E-mail:mfatimadepaula@terra.com.br

Resumo: Este artigo é fruto da pesquisa realizada em parceria entre o Núcleo de Estudos e Pesquisas em Educação Superior da Universidade Federal Fluminense e a Secretaria Municipal de Educação de Niterói, Estado do Rio de Janeiro, tendo como objetivos: a) traçar um perfil das instituições de educação superior (IES) do Município de Niterói, coletando dados acerca da sua história e da sua inserção nos cenários local, regional e nacional; b) mapear a oferta de ensino, pesquisa e extensão nestas instituições; c) subsidiar as ações da Secretaria Municipal de Educação na área educacional, contribuindo para a elaboração do Plano Municipal de Educação de Niterói; d) identificar os projetos/produtos/tecnologias, provenientes das IES, que contribuem para a formulação de políticas de desenvolvimento econômico, científico e tecnológico do município; e) identificar os projetos/produtos/tecnologias que contribuem para a elaboração de políticas na área social. A cidade de Niterói, localizada há $10,9 \mathrm{Km}$ da cidade do Rio de Janeiro, possui 16 instituições que oferecem ensino superior, 1 pública e 15 privadas, a saber: 1) Universidade Federal Fluminense; 2) Universidade Estácio de Sá; 3) Universidade Cândido Mendes; 4) Universidade Salgado de Oliveira; 5) Fundação Getúlio Vargas; 6) Centro Universitário Plínio Leite; 7) Institutos Superiores de Ensino La Salle - RJ; 8) Faculdades Integradas Maria Thereza; 9) Escola Superior de Ensino Helena Antipoff; 10) Conservatório de Música de Niterói; 11) Seminário Teológico Escola de Pastores; 12) Seminário Teológico Batista de Niterói; 13) Seminário Teológico Betel Brasileiro; 14) Seminário Teológico Congregacional de Niterói; 15) Seminário Teológico Batista Brasileiro; 16) Seminário São José de Niterói. O trabalho em questão aponta as principais características destas instituições, enfocando a sua relevância social para o município de Niterói. Para tal, abordamos a sua dimensão/perfil em Niterói e no Estado do Rio de Janeiro; a oferta de cursos no âmbito da graduação, da pós-graduação lato e stricto sensu, na cidade de Niterói; os cursos mais procurados e menos procurados e a sua relação com o mercado de trabalho; a pesquisa e a sua contribuição para o desenvolvimento do município; a extensão e o seu papel social na região. A metodologia utilizada englobou a análise de dados coletados através da internet, assim como pesquisa de campo, incluindo entrevistas realizadas nas instituições investigadas.

Palavras-chave: Cartografia. Educação Superior. Niterói. Estado do Rio de Janeiro. Desenvolvimento Regional.

\section{CARTOGRAPHY OF HIGHER EDUCATION IN THE CITY OF NITERÓI - RIO DE JANEIRO}

\begin{abstract}
This article is the result of a research carried out through a partnership between the Higher Education Studies and Research Unit of the Federal University in the City of Niterói and the Municipal

1 Este trabalho é fruto da pesquisa de mesmo título, realizada em parceria com a Secretaria Municipal de Educação de Niterói, Estado do Rio de Janeiro. A equipe que participou desta pesquisa, coordenada pela autora deste artigo, foi a seguinte: Carolina Bittencourt Nascimento, Diego Jorge Ferreira, Emiliano Côrtes Barbosa, Fernando de Souza Paiva, Izabel Cristina Mendel Souza, Maria das Graças Gonçalves Machado Sales, Maria Erineide Peixoto, Marilene Sinder, Mariza Alves Braga, Simone de Abreu Duarte, Michele dos Santos Souza e Roseli da Silva Grachet.
\end{abstract}




\begin{abstract}
Secretariat of Education of the City of Niterói, in the State of Rio de Janeiro, with the following purposes: a) to draw a profile of higher education institutions in the City of Niterói, by collecting data about their history and insertion in local, regional and national scenarios; b) to map out the provision of teaching, research and extension services in these institutions; c) to aid the actions of the Municipal Secretariat of Education in education, contributing to the elaboration of the Municipal Education Plan of Niterói; d) to identify projects/products/technologies produced by these institutions that contribute to formulate economic, scientific and technological development policies in the city; e) to identify projects/products/technologies contributing to elaborate social policies. The city of Niterói, $10.9 \mathrm{~km}$ away from the city of Rio de Janeiro, has 16 higher education institutions, 1 public and 15 private, namely: 1) Universidade Federal Fluminense; 2) Universidade Estácio de Sá; 3) Universidade Cândido Mendes; 4) Universidade Salgado de Oliveira; 5) Fundação Getúlio Vargas; 6) Centro Universitário Plínio Leite; 7) Institutos Superiores de Ensino La Salle - RJ; 8) Faculdades Integradas Maria Thereza; 9) Escola Superior de Ensino Helena Antipoff; 10) Conservatório de Música de Niterói; 11) Seminário Teológico Escola de Pastores; 12) Seminário Teológico Batista de Niterói; 13) Seminário Teológico Betel Brasileiro; 14) Seminário Teológico Congregacional de Niterói; 15) Seminário Teológico Batista Brasileiro; 16) Seminário São José de Niterói. The research shows the main features of these institutions, focusing their social relevance for the city of Niterói. To do this, we examined their size/profile in Niterói and in the State Rio de Janeiro, their provision of undergraduate and graduate programs in the city of Niterói; the programs in greater and lesser demand and their relation with the job market; their research and contribution to development of the city; the extension services and their social role in the region. The methodology employed comprised analysis of data collected through the internet, as well as field research, including interviews carried out in the institutions object of this research.
\end{abstract}

Key words: Cartography. Higher education. Niterói. State of Rio de Janeiro. Regional development.

\title{
I Introdução
}

Este artigo é fruto de uma pesquisa realizada em parceria entre o Núcleo de Estudos e Pesquisas em Educação Superior (NEPES) da Universidade Federal Fluminense e a Secretaria Municipal de Educação de Niterói, Estado do Rio de Janeiro, iniciada em abril de 2006 e concluída em setembro de 2007.

A pesquisa em foco teve como principais objetivos: a) traçar um perfil das instituições de educação superior de Niterói, coletando dados acerca da sua história e da sua inserção nos cenários local, regional e nacional; b) mapear a oferta de ensino, pesquisa e extensão nestas instituições; c) subsidiar as ações da Secretaria Municipal de Educação na área educacional, contribuindo para a construção do Plano Municipal de Educação de Niterói; d) identificar projetos/produtos/tecnologias que contribuem para a formulação de políticas de desenvolvimento econômico, científico e tecnológico do município; e) identificar projetos/produtos/tecnologias que contribuem para a elaboração de políticas na área social.

A metodologia constou da análise de dados coletados através da internet, assim como de pesquisa de campo, incluindo entrevistas realizadas nas instituições. 
O levantamento e a análise desses dados permitirão a articulação das políticas de desenvolvimento educacional, social, econômico, científico e tecnológico de Niterói. O mapeamento da oferta de ensino, pesquisa e extensão das instituições de educação superior, incluindo nesse diagnóstico os cursos de graduação e pós-graduação, os principais grupos de pesquisa, os projetos voltados para as áreas social, educacional, cultural, artística, econômica e de ciência e tecnologia, oferece um perfil destas instituições, visando identificar os principais projetos concebidos e realizados a partir das mesmas que têm relevância para a cidade de Niterói e para o Estado do Rio de Janeiro.

A pesquisa proposta revelará, também, o nível de comprometimento das instituições de ensino superior investigadas com a sociedade, permitindo a realização de considerações acerca das finalidades sociais da universidade.

\section{Niterói: uma cidade universitária por excelência}

A cidade de Niterói, fundada em 1573 pelo índio Araribóia, está localizada há 10,9 Km da cidade do Rio de Janeiro, possui 131,8 Km2, 471.403 habitantes (IBGE, 2004), tem o terceiro índice de desenvolvimento humano do país, sendo o primeiro município do Estado do Rio de Janeiro em qualificação de mão-de-obra e em inclusão digital. É considerado, ainda, o município mais escolarizado do país, segundo dados do Ministério da Educação, com o maior índice de freqüência escolar entre a população de 7 a 14 anos (97,52\%), uma taxa de alfabetização de $96,4 \%$ na população acima de 15 anos e mais de 25.000 pessoas cursando o ensino superior (NITERÓI, 2007). Niterói possui 16 instituições que oferecem ensino superior, 1 pública e 15 privadas, a saber: 1) Universidade Federal Fluminense; 2) Universidade Estácio de Sá; 3) Universidade Cândido Mendes; 4) Universidade Salgado de Oliveira; 5) Fundação Getúlio Vargas; 6) Centro Universitário Plínio Leite; 7) Institutos Superiores de Ensino La Salle - RJ; 8) Faculdades Integradas Maria Thereza; 9) Escola Superior de Ensino Helena Antipoff; 10) Conservatório de Música de Niterói; 11) Seminário Teológico Escola de Pastores; 12) Seminário Teológico Batista de Niterói; 13) Seminário Teológico Betel Brasileiro; 14) Seminário Teológico Congregacional de Niterói; 15) Seminário Teológico Batista Brasileiro; 16) Seminário São José de Niterói. Cabe ressaltar que os cursos oferecidos pelos Seminários Teológicos não são reconhecidos pelo MEC.

A Universidade Federal Fluminense (UFF) foi criada pela Lei n ${ }^{\circ}$. 3.848, de 18/12/1960, com o nome de Universidade Federal do Estado do Rio de Janeiro (UFERJ). Constituiu-se da incorporação de cinco faculdades federais 
já existentes em Niterói, três escolas estaduais e duas faculdades particulares, tendo seu nome atual homologado pela Lei $\mathrm{n}^{\circ}$. 4.831, de 5/11/1965 (VIEIRA, [s. d.], p. 10).

A UFF é hoje a instituição de educação superior de maior importância na cidade, oferecendo ensino/cursos em todas as áreas do conhecimento, no âmbito da graduação, da pós-graduação lato sensu e da pós-graduação stricto sensu. No que se refere à pesquisa e à extensão, também se destaca, possuindo projetos de pesquisa e projetos, cursos e serviços de extensão em todos os campos científicos e sociais, de grande relevância para o desenvolvimento de Niterói e do Estado do Rio de Janeiro.

A UFF oferece 65 cursos de graduação presenciais, 43 cursos de pósgraduação stricto sensu, sendo 21 Programas de Mestrado e Doutorado e 22 Mestrados, 161 cursos de pós-graduação lato sensu (dados de 2005), 2 cursos de graduação a distância (dados de 2007) e 115 cursos de extensão (dados de 2004). (UFF, 2007a)

No âmbito da cidade de Niterói, as faculdades / escolas / institutos da UFF, com seus respectivos cursos, localizam-se em diversos bairros, estando a universidade disseminada geograficamente pela cidade e mantendo com ela uma relação dinâmica e viva.

Além da sede, em Niterói, a UFF oferece ensino de graduação em municípios do interior do Estado do Rio de Janeiro, atendendo ao princípio da interiorização universitária. Os municípios do Estado do Rio de Janeiro onde a UFF oferece cursos são: Angra dos Reis, Arraial do Cabo, Bom Jesus do Itabapoana, Cabo Frio, Campos dos Goytacazes, Itaperuna, Macaé, Miracema, Nova Iguaçu, Quissamã, Rio das Ostras, Santo Antônio de Pádua, Volta Redonda (Pró-Reitoria de Assuntos Acadêmicos, dados de 2007). Possui, ainda, a unidade avançada José Veríssimo, em Oriximiná, no Estado do Pará, onde realiza atividades de extensão.

A UFF possui 19.105 alunos matriculados nos cursos de graduação presenciais, 2.864 na pós-graduação lato sensu, 2.175 alunos de Mestrado e 935 alunos de Doutorado (dados de 2005). Possui, ainda, 1.544 alunos nos cursos de graduação a distância (dados de 2005) e 609 alunos na educação básica (dados de 2006), 931 de ensino médio técnico (dados de 2004) e 125 na residência médica (dados de 2004). Com relação ao corpo docente, a UFF tem 2.213 professores, sendo 1.101 doutores, 565 mestres, 180 especialistas e 367 apenas graduados (dados de 2005). O seu quadro técnico-administrativo é constituído de 4.192 funcionários (dados de 2004) (UFF, 2007a). 
Considerando-se a relação candidato-vaga para os cursos de graduação relativa ao ano de 2007 (UFF, 2007b) podemos tecer algumas considerações sobre os cursos mais e menos procurados pelos estudantes e a sua relação com o mercado de trabalho. O curso de maior procura é o de Medicina. Em seguida, os de Comunicação Social - Publicidade e Propaganda e Comunicação Social - Jornalismo. Em quarto lugar, se apresenta o curso de Engenharia de Petróleo e em quinto, o de Educação Física.

Observando as cinco primeiras posições, constatamos que a demanda se concentra, por um lado, no tradicional curso de Medicina e, por outro, em cursos novos como o de Engenharia de Petróleo, que possui estreita relação com o mercado de trabalho em expansão na cidade de Niterói e em municípios próximos, que têm ampliado a sua atuação nesta área, através de empresas como a Petrobrás e outras vinculadas à indústria naval. A forte demanda apresentada para o campo da Comunicação Social pode ser explicada por esta profissão ser considerada de grande potencial mercadológico em uma sociedade de consumo regida pela mídia em geral. Dentro da perspectiva de um modismo de mercado, pode ser interpretada a grande procura pela Educação Física, num momento em que o cuidado com o corpo, o apelo por um físico bem preparado, atlético e esbelto assumem valores supremos na contemporaneidade.

Os cursos menos procurados são aqueles de menor prestígio social e que apresentam menos possibilidades no âmbito do mercado de trabalho, tais como: Estatística, Engenharia Agrícola, Letras, Física, Química (Licenciatura Noturna), além de Matemática (Santo Antônio de Pádua) e Serviço Social (Bom Jesus do Itabapoana), cidades do interior do Estado do Rio de Janeiro.

Os cursos de pós-graduação lato sensu oferecidos pela UFF, na sua maioria, são chamados de autofinanciáveis, sendo cobrados dos estudantes e apresentando valores diferenciados, de acordo com a área. A área de Odontologia é a que oferece cursos mais caros, chegando a cobrar R $\$ 36.150,00$ por um curso de 30 meses em Ortodontia e Ortopedia Facial. Em segundo lugar, está a área tecnológica, que também cobra caro por seus cursos, como R\$18.000,00 por um curso de Engenharia de Soldagem de 480h. A área de ciências humanas e sociais, em geral, apresenta custos mais modestos, como os cursos do Instituto de Ciências Humanas e Filosofia, alguns deles possuindo valores abaixo de R\$ 2.000,00 (dados de 2007). Os valores cobrados pelos cursos de pós-graduação lato sensu refletem, em grande medida, a hierarquia existente entre as áreas médica e tecnológica, de um lado, e humanas e sociais, de outro, sendo as primeiras, ainda, marca de prestígio social e, pelo menos no imaginário social, 
fontes de melhores empregos e salários. Dentro desta lógica privatizante, estão os dois mestrados profissionais oferecidos pela UFF hoje: Mestrado Profissional em Enfermagem Assistencial, 18 meses de duração, custo total de R $\$ 22.475,50$ e Mestrado Profissional em Sistema de Gestão, 2 anos, custo de R \$ 28.850,00 (dados de 2007).

A pós-graduação lato sensu e, muito recentemente, os mestrados profissionalizantes representam o terreno movediço por onde entra a privatização do ensino nas universidades públicas e a UFF não é exceção, pois aderiu ao forte apelo do governo na direção da diversificação de fontes de financiamento para as universidades federais. É importante salientar, contudo, que este processo de privatização não é conseqüência apenas das políticas neoliberais provenientes de fora dos muros da universidade, mas deve-se, em grande parte, à adesão dos atores envolvidos internamente, que produzem e reproduzem práticas privadas no contexto das instituições públicas (PAULA; AZEVEDO, 2006).

A Universidade Estácio de Sá (UNESA) é considerada uma das maiores universidades privadas brasileiras. Esse dado tem como base o número de alunos matriculados nos cursos de graduação da instituição, que apenas no Estado do Rio de Janeiro atinge 115.891 alunos (MEC. INEP, 2007).

A UNESA iniciou suas atividades no final da década de 1960, quando João Uchôa Cavalcanti Netto e José Lisboa da Gama Malcher, juízes de Direito, resolveram criar os cursos jurídicos de pós-graduação e para isso, constituíram uma sociedade civil cujo objetivo inicial era aperfeiçoar e preparar os estudantes de Direito para a realização de concursos públicos nessa área. Com o sucesso desse empreendimento, João Uchôa resolveu criar a Faculdade de Direito e para isso convidou José Lisboa da Gama Malcher e João Morisi para construírem o projeto. Nasce assim, com o curso de Direito, a Faculdade de Direito Estácio de Sá (FADES), em 1970 (UNESA, 2007a).

No decurso desses 37 anos, os cursos de Direito se consolidaram e hoje estão distribuídos nos campi que a universidade possui no Estado do Rio de Janeiro, com cerca de 30 mil alunos matriculados apenas nos cursos de Direito, entre formandos e em formação. Neste cenário, a UNESA é responsável por cerca de 5\% das matrículas em Direito no Brasil.

A UNESA possui, na atualidade, 40 campi no âmbito do Estado do Rio de Janeiro, 8 fora do Estado (3 em Minas Gerais, 1 em Mato Grosso do Sul, 1 em São Paulo, 1 em Santa Catarina e 2 no Espírito Santo), além de um campus virtual, que oferece 46 cursos on line, com aulas presenciais, contemplando a graduação e a pós-graduação em Direito, assim como o Ensino Médio. 
No cenário do Estado do Rio de Janeiro, possui 4.835 professores, sendo 497 doutores, 2.023 mestres, 1.350 especialistas e 965 graduados (MEC. INEP, 2007).

Geograficamente, o campus da UNESA, em Niterói, se localiza no centro da cidade, em posição estratégica, ficando a 200 metros da estação das barcas. Além do campus de Niterói, que em 2003 se tornou o segundo maior da universidade, possui ainda, nesta cidade, a Clínica de Fisioterapia (FisioNiterói), com equipamentos de última geração e o Serviço de Psicologia Aplicada, ambos localizados no centro.

Pelo número total de alunos matriculados nos cursos de graduação da unidade de Niterói, 12.134, pode ser considerada uma das maiores universidades privadas da região fluminense (11.177 alunos matriculados nos cursos de graduação de maior duração e 957 alunos matriculados nos cursos politécnicos). Possui 719 docentes neste município, sendo 89 doutores, 373 mestres, 216 pós-graduados e 41 graduados, além de 158 funcionários do quadro técnicoadministrativo (dados de 2006).

Os cursos de graduação mais procurados pelos estudantes, no âmbito de Niterói, são: Direito (3575 alunos matriculados), Administração (1464 alunos) e Comunicação Social (1221). Os menos procurados são Secretariado Executivo Trilingüe, que deixou de ser oferecido em 2007, Ciências Contábeis e Ciências Biológicas, com menos de 50 alunos matriculados (dados de março de 2006). Estes dados refletem a procura pelos cursos mais tradicionais como Direito, que tem uma tradição na UNESA e no mercado de trabalho como um todo; o curso de Comunicação Social, com dito no caso da UFF, tem atraído os estudantes pelo forte apelo da mídia e sua influência na sociedade atual. Os cursos menos procurados pelos estudantes, na UNESA de Niterói, pertencem a áreas de menor prestígio social e que apresentam menos possibilidades de empregos bem remunerados.

Cabe salientar que os cursos mais caros são, em geral, aqueles que têm maior prestígio social, melhores possibilidades de emprego no mercado de trabalho, mais tradição e maior procura pelos estudantes, tais como Direito, Comunicação Social (Jornalismo e Publicidade e Propaganda), Engenharia de Produção, Psicologia, Relações Internacionais e Engenharia de Petróleo de Gás. Por outro lado, os cursos mais baratos são aqueles que possuem menor prestígio social, piores possibilidades de emprego no mercado de trabalho, menos tradição e menor procura pelos alunos, como Letras, Pedagogia, Ciências Biológicas, Ciências Contábeis. 
Além dos cursos de graduação tradicionais, a UNESA oferece vários cursos politécnicos, de curta duração. A oferta destes cursos obedece a interesses de mercado da instituição, ficando nítida a intenção de atingir clientes para as áreas de indústria naval, petróleo e gás, financeira, de propaganda e marketing, telecomunicações, turismo, dentre outras, com forte apelo hoje na região fluminense. Cabe ressaltar que os cursos politécnicos, tendo uma duração que varia de 4 a 5 semestres, atraem uma clientela que procura cursos superiores mais rápidos, menos custosos do ponto de vista financeiro e intelectual, representando uma formação aligeirada em âmbito universitário.

No âmbito da pós-graduação lato sensu, a UNESA tem oferecido vários cursos em diversas áreas, em Niterói. Estes cursos têm carga horária que varia de 348 horas no Curso de Direito Público a 500 horas no de Terapia Cognitiva e suas Aplicações e valores que variam de $\mathrm{R} \$ 4.784,00$ para o Curso de Docência do Ensino Superior (360 horas) a R\$ 7.686,00 para o de Petróleo e Gás (396 horas), representando uma enorme fonte de lucro para a instituição.

Esta instituição não oferece pós-graduação stricto sensu em Niterói, apenas na cidade do Rio de Janeiro: Mestrado em Educação e Mestrado e Doutorado em Direito.

$\mathrm{Na}$ área da extensão universitária, destacam-se a Clínica de Fisioterapia, que atende pacientes portadores de patologias, o Escritório de Assistência Jurídica Gratuita, que conjuga a prática do ensino do Direito com o atendimento à comunidade carente que não pode pagar pelos serviços jurídicos e o Serviço de Psicologia Aplicada, apresentando atendimento psicoterápico a idosos, adultos, adolescentes e crianças a preços simbólicos muito reduzidos.

Cabe ressaltar, ainda, os 151 cursos de extensão gratuitos oferecidos mensalmente em Niterói, com uma média de 16 horas, abertos ao público em geral (UNESA, 2007b). É cobrada uma taxa opcional de R\$15,00 para aqueles que desejarem obter o certificado. Estes cursos abrangem uma grande variedade de áreas, sendo alguns mais instrumentais e pragmáticos do que outros, não tendo o menor status universitário, como: Administração de Pequenos Hotéis e Pousadas, Etiqueta Social, Fotografia Profissional, Cabeleireiro, Crimes na Internet, Dança de Salão, Jardinagem e Paisagismo, Mercado de Ações, Técnicas de Maquiagem, Ponto Cruz, Turismo de Aventura, Vitrine, Moda e Tendências. É importante salientar o caráter gratuito dos mesmos numa universidade privada em sentido estrito, confrontando com cursos e serviços de extensão que são cobrados nas universidades públicas, na atualidade.

Em 2 de junho de 1902, sob a superintendência da recém-criada Sociedade Brasileira de Instrução, organizou-se a Congregação da Academia do Comércio 
do Rio de Janeiro, com o objetivo de instaurar cursos que proporcionassem aos jovens uma cultura comercial sólida. Em 1919, o Diretor da Academia de Comércio, Conde Cândido Mendes de Almeida, baseado na decisão do $1^{\circ}$ Congresso Americano de Expansão Econômica e Ensino Comercial, transformou o curso superior de economia em Faculdades de Ciências Econômicas. Neste mesmo ano, assiste-se à fundação da Faculdade de Ciências Políticas e Econômicas do Rio de Janeiro, a primeira escola superior de Economia do Brasil (UCAM, 2006).

Nos anos 1950, a Academia, que continuava a manter economicamente a Faculdade, transforma-se na atual Escola Técnica de Comércio Cândido Mendes, dedicada exclusivamente ao ensino médio. Cândido Mendes de Almeida Junior funda a Faculdade de Direito Cândido Mendes, sediada no secular Convento do Carmo. O curso teve início em 5 de maio de 1953 e instaurou mais um padrão de excelência - agora no âmbito das Ciências Jurídicas.

Em 1997, após o cumprimento das exigências da Lei de Diretrizes e Bases da Educação Nacional - LDB, a Universidade Cândido Mendes (UCAM) foi criada por Decreto Federal (MEC. INEP, 2007).

A Universidade atua essencialmente no Estado do Rio de Janeiro, nos municípios de Campos, Niterói, Nova Friburgo e Rio de Janeiro, estendo-se ao Estado do Sergipe através de uma parceria com a Faculdade Sílvio Romero, oferecendo cursos de pós-graduação lato sensu em várias áreas. Possui uma unidade no Estado de Santa Catarina, com cursos de MBA. A UCAM possui, também, escritórios ou pólos dos cursos de pós-graduação lato sensu e extensão à distância nas cidades de Belém-PA, Brasília - DF, Campinas-SP, FortalezaCE, Cuiabá-MT, Belo Horizonte-MG, Cascavel-PR, Cachoeiro do Itapemirim - ES, Ipatinga - MG e Florianópolis-SC.

AUCAM possui 16.347 alunos matriculados na graduação e 729 professores, no âmbito do Estado do Rio de Janeiro: 117 são doutores, 263 são mestres, 105 são especialistas e 244 são graduados (MEC. INEP, 2007).

O campus de Niterói foi criado em 1998, estando localizado no Centro, próximo às barcas. Nos cursos de graduação de Niterói estão matriculados 3.060 alunos e envolvidos 297 professores, sendo $8 \%$ doutores, $52 \%$ mestres, $30 \%$ especialistas e $10 \%$ graduados. O quadro técnico-administrativo da UCAM em Niterói é constituído de 97 funcionários (dados de 2006) (ASSUMPÇÃO, 2006).

A unidade de Niterói oferece dez cursos de graduação, sendo sete ligados à graduação tradicional e três voltados para a formação de tecnólogos. Destes cursos, os mais procurados pelos estudantes são os de Comunicação Social, com 
580 alunos matriculados, Engenharia de Produção, com 529 alunos e Direito, com 510 alunos matriculados. Os menos procurados são: Gestão Empresarial de Marketing, Curso Seqüencial de Moda e Desenvolvimento de Software, com respectivamente 96, 111 e 115 alunos matriculados (dados de 2006) (ASSUMPÇÃO, 2006); (BERLIN, 2006); (MONCLAR, 2006). De forma semelhante ao quadro traçado da UFF e da UNESA, aqui também os cursos mais procurados são os de maior prestígio social e que oferecem melhores possibilidades de emprego, e, no caso específico, os cursos menos procurados são os de menor duração, que formam tecnólogos, e, portanto, são menos legitimados socialmente e no âmbito do mercado de trabalho.

No âmbito da pós-graduação lato sensu, a UCAM oferece, em Niterói, uma variedade de cursos, nas áreas de educação, saúde, direito, marketing, administração e finanças, moda. Todos estes cursos têm duração de 12 meses e um custo total de $\mathrm{R} \$ 2.840,00$ para os estudantes (UCAM, Instituto a Vez do Mestre, 2006).

No que diz respeito à extensão, há o Núcleo de Prática Jurídica, ligado ao curso de graduação em Direito. Este núcleo, além de contribuir para a formação dos bacharéis em Direito, presta atendimento jurídico gratuito à população de baixa renda, localizando-se no centro da cidade de Niterói, assim como a própria universidade.

A Universidade Salgado de Oliveira é originária de uma pequena escola em São Gonçalo, município do Estado do Rio de Janeiro, que se transformou no Colégio Dom Hélder Câmara. Muitas transformações ocorreram até que, em 1976, iniciaram-se os primeiros cursos superiores, com a criação da Faculdade de Educação, Ciências e Letras de São Gonçalo.

Em 1985, já eram 10 cursos e a instituição transformava-se em Faculdades Integradas de São Gonçalo. Com a aprovação da carta-consulta, teve início o processo de criação da universidade, em 1990, concretizado, após três anos, pela Portaria Ministerial $n^{\circ} 1283$, de 8 de setembro de 1993, nascendo então a Universidade Salgado de Oliveira (UNIVERSO).

Quando de seu reconhecimento em 08/09/1993, a UNIVERSO já contava com dois campi - São Gonçalo e Niterói - e no Estado do Rio de Janeiro oferecia cursos de pós-graduação, expandindo-se também para diversas unidades da Federação (UNIVERSO, 2007). O campus de Niterói está localizado no centro da cidade.

Com base em seu Plano de Expansão, a UNIVERSO abriu, a partir de 1996, os campi de Campos dos Goytacazes (Sub-judice), no Estado do Rio de Janeiro, e de Goiânia (Sub-Judice), no Estado de Goiás. Em 2000, abriu o campus de 
Recife (Sub-Judice), em Pernambuco e, em julho de 2003, começaram as atividades no campus de Juiz de Fora (Sub-Judice), em Minas Gerais. Em 2004, a UNIVERSO chega à capital mineira, com a abertura do campus de Belo Horizonte (Sub-Judice). No mesmo ano, surgem mais três novos campi, com a criação das unidades de Osasco (SP) (Sub-Judice), Brasília (DF) (Sub-Judice) e do Rio de Janeiro (RJ) (Sub-Judice). Em 2005, a UNIVERSO abre seu segundo campus na Região Nordeste, na cidade de Salvador (MEC/INEP, 2007).

Esta universidade, considerando-se a quantidade de campi/unidades que estão sub-judice (sob apreciação judicial), segundo informação obtida através do site do Ministério da Educação e Cultura e também a avaliação dos seus cursos de graduação pelo mesmo ${ }^{2}$, tem se expandido por vários Estados e regiões brasileiras sem a preocupação fundamental com a qualidade do ensino oferecido, tendo esta instituição, contraditoriamente considerada como privada filantrópica pelo MEC, um viés nitidamente mercadológico, voltado para a obtenção do lucro.

No âmbito do Estado do Rio de Janeiro, a UNIVERSO possui 58.247 alunos matriculados nos seus cursos de graduação e um total de 1.222 docentes, sendo 98 doutores, 399 mestres, 576 especialistas e 149 graduados ( MEC. INEP, 2007) ${ }^{3}$.

Além dos cursos de graduação, a UNIVERSO oferece, em Niterói, mais de trinta cursos no âmbito da pós-graduação lato sensu, em distintas áreas, com em média 15 meses de duração, atendendo a uma demanda diversificada (UNIVERSO, 2007). Existem cursos para todos os bolsos. Os mais caros são os da área de Odontologia: Prótese Dentária, 24 meses, custo total de R \$ 24.000,00; Odontopediatria, 18 meses, custo total de R \$21.920,04; Radiologia Odontológica e Imaginologia, 18 meses, custo total de R \$10.319,94. Os mais baratos são os de Ciências da Atividade Física: promoção da saúde, cultura e sociedade, 10 meses, custo total de R\$ 1.255,60; História do Brasil: sociedade,

2 Na avaliação dos cursos oferecidos no Município de Niterói, primeiro no âmbito do Exame Nacional de Cursos, conhecido como Provão, o conceito de vários cursos de graduação, como o de Administração, caiu de C em 2001 para D em 2002 e 2003; o de Ciências Biológicas caiu de C em 2002 para D em 2003; o de Ciências Contábeis caiu de D em 2002 para E em 2003; o de Direito caiu de D em 1999 para E em 2000, 2001, 2002 e 2003; o de Odontologia permaneceu D nos anos de 2002 e 2003; e o de Psicologia caiu de B em 2002 para C em 2003. No ENADE, Exame Nacional de Desempenho dos Estudantes, que substituiu o Provão a partir de 2004, os conceitos dos cursos de graduação oferecidos pela UNIVERSO também não são os melhores, a saber: o curso de Engenharia de Produção recebeu conceito 1 em 2005 e os cursos de Ciências Biológicas (Licenciatura), História (Licenciatura), Matemática (Licenciatura) e Pedagogia receberam conceito 2 no ENADE, em 2005, num universo de notas de 1 a 5 , onde 5 representa a nota mais alta (MEC/ INEP, 2007).

3 A instituição não nos disponibilizou os dados sobre corpo docente e discente referentes à cidade de Niterói. 
política e cultura, 13 meses, custo de R \$ 1.588,86; História Contemporânea, 15 meses, custo de R $\$ 2.333,40$ (valores de 2007) (UNIVERSO, 2007). A pósgraduação lato sensu representa, assim, uma fonte inesgotável de recursos e de lucro para as instituições de educação superior.

No que se refere à pós-graduação stricto sensu, a UNIVERSO oferece os seguintes cursos em Niterói: Ciências da Atividade Física (Mestrado), Psicologia Social (Mestrado) e História (Mestrado). Estes mestrados acadêmicos iniciaram as suas atividades no ano de 2007, contudo já se encontram avaliados e reconhecidos pela Coordenação de Aperfeiçoamento de Pessoal de Nível Superior (CAPES), com nota 3 (UNIVERSO, 2007).

Como trabalhos de extensão desenvolvidos pela UNIVERSO, em Niterói, destacamos (UNIVERSO, 2007):

a) Universo Solidário, tendo como objetivo, dentre outros, o atendimento à comunidade através de ações de cidadania nas áreas de saúde, educação, meio ambiente e direitos humanos;

b) Planeta Chamado João, tendo como objetivo promover a integração da universidade com as escolas de ensino médio, buscando informar sobre a importância da escolha profissional e a importância do ensino superior na formação acadêmica.

A Fundação Getúlio Vargas (FGV) surgiu em 20 de dezembro de 1944. Seu objetivo inicial era preparar pessoal qualificado para a administração pública e privada do país. Na época, o Brasil já começava a lançar as bases para o crescimento que se confirmaria nas décadas seguintes.

A FGV inaugurou, no Brasil, a graduação e a pós-graduação stricto sensu em administração pública e privada, bem como a pós-graduação lato sensu em economia, psicologia, ciências contábeis e educação. Esta instituição aparece na pesquisa Datafolha (out. 2005) como a escola com os melhores MBAs do Brasil, reconhecida pelo mercado como a preferida pelos presidentes de empresas nacionais.

AFGV possui seus núcleos principais em Brasília (DF) e em São Paulo (SP), mantendo instituições conveniadas em vários Estados e cidades brasileiras, dentre as quais Rio de Janeiro e Niterói.

A Capital Humano Tecnologia e Treinamento Ltda. iniciou as suas atividades em fevereiro de 1996, partindo da experiência acumulada de seu principal executivo, Aloysio Loyola, na formação e desenvolvimento de pessoas para o mercado financeiro, desde a década de 80 (FGV, Núcleo Niterói, 2007). Em 1997, a atuação diferenciada no mercado financeiro propiciou à Capital Hu- 
mano firmar um convênio com a Fundação Getúlio Vargas para a realização dos programas de educação continuada do Projeto FGV Management, criado pela FGV para expandir a sua atuação nacional contando com núcleos a ela associados para maior divulgação dos seus cursos e da sua metodologia.

O total de professores da Capital Humano, que abrange as unidades de Niterói, Petrópolis e Nova Friburgo, é de 235, sendo 34\% doutores, 46\% mestres e $20 \%$ especialistas. No ano de 2006, havia 650 alunos matriculados em Niterói e, em 2007, 550. O quadro técnico-administrativo em Niterói conta com 31 funcionários. A partir destes dados, conclui-se que a abrangência da FGV nesta cidade é pequena, oferecendo apenas cursos de pós-graduação lato sensu e cursos de extensão, estando situada no centro da cidade (BASTOS, 2007).

Segundo informações obtidas junto à instituição (2007), o curso de pósgraduação mais procurado em Niterói é o MBA em Gestão Empresarial. Todos os MBAs têm uma carga horária, em média, de 432 h/a, 18 meses e custam $\mathrm{R} \$ 18.226,00$, salvo descontos e condições especiais para grupos. O curso de especialização em Administração de Empresas tem a mesma carga horária e custa $\mathrm{R} \$ 10.333,00$ e o curso de Advogado Cível tem um custo de $\mathrm{R} \$ 14.586,00$ (valores de 2007). Ou seja, são cursos caros, dirigidos a executivos que podem pagar pelo status de ter uma pós-graduação com a marca da FVG.

A FGV oferece, em Niterói, cursos de extensão / atualização variados em Administração de Empresas, nas áreas de Contabilidade e Finanças, Logística, Operações, Recursos Humanos, e Marketing e Vendas, com, em média, 24h/a e custo de $\mathrm{R} \$ 855,00$ (2007).

O Centro Universitário Plínio Leite (UNIPLI) iniciou a sua trajetória em 1974, como Faculdade Niteroiense de Formação de Professores. Em 1991, com a incorporação de novos cursos, passou a ser denominada Faculdade Niteroiense de Educação, Letras e Turismo. Ultrapassando as expectativas de crescimento, foi elevada à categoria de Faculdades Integradas Plínio Leite, em 1994, e, por fim, a Centro Universitário Plínio Leite, em 1999 (UNIPLI, 2007a).

O UNIPLI conta com 363 professores, sendo 10,5\% doutores, 57,2\% mestres, $21,5 \%$ especialistas e $10,8 \%$ graduados. Possui um total de 283 funcionários, 7196 alunos em cursos de graduação (dados de 2007), 628 na pós-graduação lato sensu (dados de 2006) e 70 na pós-graduação stricto sensu (dados de 2007) (SOUZA, 2007).

O Centro Universitário Plínio Leite, atualmente, é constituído por 3 unidades de ensino superior em Niterói: Sede, centro; Centro-Sul, centro; Camboinhas, região oceânica; além da unidade de Itaboraí, município vizinho de Niterói, Estado do Rio de Janeiro. A sede oferece os cursos de Administração, 
Arquitetura e Urbanismo, Ciência da Computação, Ciências Biológicas-Biomedicina, Ciências Contábeis, Comunicação Social, Direito, Enfermagem, Farmácia, Fisioterapia, Letras, Medicina Veterinária, Serviço Social e Turismo. A unidade de Camboinhas oferece o curso de Direito; a Centro-sul, os cursos de Educação Física, Tecnologia em Design de Moda e Tecnologia em Gestão Ambiental; a de Itaboraí, o Curso de Veterinária, sendo a sede do Hospital de Clínicas Veterinárias.

Vários cursos de pós-graduação lato sensu são oferecidos anualmente, nas seguintes áreas de conhecimento, podendo ter caráter de docência ou não: Educação; Ciências Exatas e da Terra; Engenharias e Ciências Tecnológicas; Ciências Biológicas e da Saúde; Ciências Humanas e Sociais; e Letras e Artes. Os custos destes cursos são modestos, quando comparados com os das demais instituições analisadas, pois o valor da mensalidade é de R $\$ 130,00$, sendo que para ex-alunos ela cai para $\mathrm{R} \$ 90,00$. Os valores modestos dos cursos de pós-graduação lato sensu contradizem a realidade das instituições privadas em sentido estrito, como é o caso do UNIPLI, pois este é um terreno propício para a mercantilização do ensino superior, como vimos, trazendo muito lucro para os empresários do ensino. Mesmo instituições tidas como privadas filantrópicas, como é o caso da UNIVERSO, já analisada, cobram muito mais caro por estes cursos.

No âmbito da pós-graduação stricto sensu, o UNIPLI oferece o Mestrado Profissional em Ensino de Ciências da Saúde e do Ambiente, reconhecido pela CAPES e avaliado com conceito 3 . Este curso tem duração de 24 meses e custo de R $\$ 15.120,00$ (2007), bem mais elevado do que o custo dos cursos de pósgraduação lato sensu (UNIPLI, 2007b; SOUZA, 2007).

Os Centros Universitários têm aspecto diferenciado das universidades, caracterizados pela não obrigatoriedade da existência de atividade de pesquisa, tanto nas áreas básicas como nas aplicadas. Entretanto, o UNIPLI considera a pesquisa como um princípio educativo, em que a investigação científica está presente na proposta pedagógica, na busca da autonomia intelectual de docentes e discentes, em projetos organizados com a preocupação de interações com a realidade social.

Além dos vários cursos de extensão oferecidos à comunidade de Niterói, destacamos as seguintes atividades de extensão realizadas pelo UNIPLI:

a) Projeto Clínica da Alegria - valorização da vida pelo sorriso: oriundo do Departamento de Enfermagem, sob a condução de alunos integrantes do curso, desenvolve-se nos Hospitais da Rede Municipal/Estadual, envolvendo 
pacientes infantis internados em todos os setores: emergência, enfermaria, salas de espera e CTI. Tem por objetivo minimizar as diferenças entre o espaço familiar e o hospitalar, contribuindo para uma melhor adaptação da criança à nova realidade social.

b) Programa de Alfabetização Solidária: são atendidos, em classes de alfabetização, jovens e adultos de vários municípios do Estado da Paraíba. Além das atividades mensais de capacitação continuada dos professores alfabetizadores dessas comunidades e das visitas de acompanhamento e supervisão às salas de aula, são desenvolvidas ações culturais como o Projeto Formação do Leitor e o Projeto Resgate da Comunidade e Fortalecimento da História - Memória de Jovens e Adultos. Pretende-se, desta forma, contribuir para a construção da cidadania, através da ação crítica e reflexiva feita sobre a realidade social dos docentes e das comunidades envolvidas.

Os Institutos Superiores de Ensino UNILASALLE - RJ são uma parte da obra educativa do pedagogo João Batista de La Salle, implementada por seus herdeiros, os Irmãos das Escolas Cristãs ou Lassalistas. Estes formam a maior congregação docente da Igreja e estão atualmente disseminados por todo o mundo, dirigindo estabelecimentos em todos os graus e setores do ensino. Hoje, a ação lassalista está presente em 83 países do mundo, contando com 7694 Irmãos, 63 mil educadores, 1500 comunidades educativas e mais de um milhão de alunos em todos os tipos de escolas, de obras culturais e de assistência social de cunho educativo (UNILASALLE, 2007).

A Comunidade Lassalista existe para servir à educação desde 1680. No Brasil, ela está presente há 100 anos e, em Niterói, há 52 anos. Em nosso país, os Lassalistas fundaram em 1907 a sua primeira escola para os filhos dos operários que residiam no bairro Navegantes, em Porto Alegre. Hoje, são mais de 200 irmãos e 2500 educadores, em 43 comunidades educativas, que atendem mais de 50 mil crianças, jovens e adultos, em 11 estados brasileiros.

Em Niterói, os Institutos Superiores de Ensino La Salle têm origem no Instituto ABEL (Associação Brasileira de Educadores Lassalistas), instituição de ensino fundamental e médio de excelência, criado nos anos de 1950 neste município. Após um crescimento acelerado do Instituto ABEL e ampla procura por educação de alta qualidade, surgem os Institutos Superiores de Ensino La Salle.

O Instituto Superior de Educação La Salle foi inaugurado no dia 10 de maio de 2003, autorizado pela Portaria 1.164, de 11 de junho de 2001, e o Instituto Superior de Ciências Humanas e Filosofia La Salle foi autorizado pela Portaria 
218, de 14 de janeiro de 2004 (MEC/INEP, 2007). Ambos estão situados no bairro de Santa Rosa.

Os cursos de graduação em Administração, Ciências Contábeis, Computação, Direito, Relações Internacionais pertencem ao Instituto Superior de Ciências Humanas e Filosofia La Salle e os cursos de Licenciatura em História e Pedagogia pertencem ao Instituto Superior de Educação La Salle.

Os Institutos Superiores de Ensino La Salle têm, atualmente, um corpo docente constituído por 141 professores, sendo 54 doutores, 85 mestres e 2 especialistas. Possuem cerca de 80 funcionários, 987 alunos matriculados nos cursos de graduação e 110 alunos nos cursos de pós-graduação lato sensu (SOUZA, 2007).

Os cursos de graduação mais procurados pelos estudantes, nesta instituição, são os de Administração, Relações Internacionais e Direito, pois possuem mais alunos matriculados e a relação candidato-vaga é maior para estes cursos. Não é por acaso que os custos mais elevados são para os referidos cursos, que apresentam mais prestígio social, oferecem, pelo menos no imaginário dos estudantes, melhores possibilidades no mercado de trabalho e, por isto, são mais procurados. Por outro lado, os cursos Normais Superiores (em processo de extinção), de Pedagogia e Licenciatura em História são os mais baratos, possuindo menos prestígio social e sendo menos procurados pelos alunos.

No que se refere à pós-graduação lato sensu, são oferecidos vários cursos, dentre eles, o de Gastronomia. Surpreende-nos um curso de pós-graduação em Gastronomia, tema que, no passado, certamente não seria alvo do ensino superior, sobretudo no nível da pós-graduação. Oferecer cursos os mais variados e inusitados pode ser uma estratégia das instituições de ensino superior para ampliar a sua margem de lucro, atraindo fatias cada vez mais diversificadas de mercado. Aqui também os custos dos cursos refletem o seu status social e as possibilidades de empregos mais bem remunerados: o curso de Relações Internacionais custa ao estudante R \$ 6.500,00, o MBA Gestão Estratégica de Empresas tem um custo de R \$ 5.400,00, mesmo valor do curso de Produção Cultural (valores de 2007). Os demais cursos de pós-graduação possuem custos menores.

A história das Faculdades Integradas Maria Thereza (FAMATh) teve origem no Educandário Maria Thereza, fundado no início dos anos 40 do século XX, que até os anos 70 consolidou-se como instituição de ensino de $1^{\circ}$ e $2^{\circ}$ graus (BRAGA, 2006); (FAMATh, 2006).

As Faculdades Integradas Maria Thereza (FAMATh), como instituição de ensino superior privada em sentido estrito, são mantidas pelo Instituto de Ciên- 
cia e Tecnologia Maria Thereza Ltda (ICTMTh), fundado em 02/06/1973, pela educadora Edith Salles Lima, com a finalidade de promover o desenvolvimento científico e tecnológico em áreas prioritárias. Foram criadas pelo Decreto Federal $\mathrm{n}^{\circ}$ 75.507, de 18/03/1975. (MEC. INEP, 2007).

Instituição de amplitude local atuante na cidade de Niterói, destaca-se por ter sido uma das primeiras instituições privadas de nível superior do município. Valendo-se de sua tradição e pioneirismo vocacional nas áreas de Psicologia e Biologia, oferece também apoio nas áreas de meio-ambiente e saúde.

O campus I - sede - localiza-se no bairro de São Domingos, onde funcionam os cursos de Psicologia, Ciências Biológicas, Biologia Marinha e Pedagogia; o campus II está situado no bairro de Rio do Ouro, divisa com os municípios de São Gonçalo - RJ e Maricá - RJ, onde funciona o curso de Educação Física.

As FAMATh possuem 100 professores, sendo 18 doutores, 69 mestres, 12 especialistas e 1 graduado, e um total de 1754 alunos matriculados em seus cursos de graduação (MEC. INEP, 2007).

$\mathrm{Na}$ graduação, os cursos mais procurados são, segundo os dados do MEC relativos ao Censo de 2005: Psicologia (590 anos matriculados), Formação de Professor de Biologia ou Licenciatura em Ciências Biológicas (403 alunos) e Educação Física (381 alunos). O curso de Pedagogia é o que possui menos alunos matriculados (209).

Estes dados relacionam-se, nesta instituição, com a tradição dos cursos de Psicologia e Ciências Biológicas, ambos iniciados em 1975. Por ter sido o primeiro curso de Psicologia de Niterói, insere, com relativa facilidade, os profissionais por ele formados no mercado de trabalho. Cabe ressaltar que o curso de Biologia Marinha das FAMATh, também muito procurado hoje pelos estudantes, foi o primeiro curso de Biologia Marinha do Brasil e da América do Sul, tendo formado muitos professores que atuam na área biológica da UFF. No caso da Educação Física, este curso, como dito anteriormente, tem sido muito procurado atualmente pelos estudantes pelas possibilidades de inserção múltipla no mercado de trabalho, numa sociedade que valoriza enormemente o cultivo do corpo: o profissional de educação física pode atuar como autônomo e/ou em instituições e órgãos de prestação de serviços em atividade física, desportiva e/ou recreativa; instituições de educação públicas e privadas; empresas públicas e privadas; academias; clubes; centros de lazer; condomínios; centros de estética; instituições e órgãos de saúde, dentre outros.

Interessante notar que, como nas demais instituições investigadas, em geral, os valores dos cursos acompanham o seu prestígio social, a sua tradição 
e a maior ou menor procura pelos estudantes. No caso das FAMATh, o curso de Psicologia tem um custo mensal de R\$ 544,50, os de Ciências Biológicas, Biologia Marinha e Educação Física custam R\$381,15 e o de Pedagogia R\$ 280,00 (SILVA, 2007).

As FAMATh oferecem mais de cinqüenta cursos de pós-graduação lato sensu nas mais diversas áreas: humanas e sociais, biomédicas e da saúde, ciências naturais, meio-ambiente, tecnológicas. No entanto, eles só são abertos se houver demanda, acompanhando o fluxo do mercado, com ofertas semestrais. O seu período de duração varia de 12 a 24 meses, com custos também variados, para todos os bolsos. Dos cursos oferecidos no primeiro semestre de 2007, os mais baratos são os de Psicologia Hospitalar e da Saúde, 13 meses e de Psicologia Jurídica, 13 meses, com custo total de $\mathrm{R} \$ 2.000,00$ e o mais caro é o de Acupuntura, 24 meses, custo total de R\$ 5.570,00. Do rol dos cursos, surpreende-nos a oferta de alguns que, a priori, não têm o menor status universitário, sobretudo para o nível de pós-graduação: Relacionamento Amoroso e Sexualidade Humana (13 meses, R\$ 3.300,00), Massagem Científica (15 meses, R\$ 3.650,00), além de Carnaval e Gestão Estratégica de Eventos Especiais, e Administração de Restaurantes e Serviços de Alimentação, cursos que não estão sendo oferecidos neste semestre.

Embora as Faculdades Integradas não sejam obrigadas por lei a realizarem pesquisa, as FAMATh vêm incentivando os seus corpos docente e discente na direção das atividades de pesquisa e da produção acadêmica. Destacamos as pesquisas realizadas na área de Biologia Marinha, com tradição na instituição.

Na área da extensão, as FAMATh, por meio do Curso de Psicologia, prestam atendimento à comunidade niteroiense, com cerca de 400 pacientes atendidos por mês, nas áreas de Psicologia da Família, da Infância e da Terceira Idade, através de seu Serviço de Psicologia Aplicada. A instituição possui vínculo com o Projeto Alfabetização Solidária, do Governo Federal, nos estados de Pernambuco, Bahia, Goiás e Rio Grande do Norte, cedendo seus profissionais e alunos para atuarem nas frentes de atuação do referido projeto. $\mathrm{Na}$ área de Educação, são oferecidas oficinas gratuitas de atualização a professores, bem como reforço a alunos carentes da rede pública, além de um programa de relacionamento com as escolas que oferecem ensino médio na cidade de Niterói, buscando auxiliar os alunos na escolha de suas profissões, nas diversas áreas existentes. As FAMATh oferecem uma ampla variedade de cursos de extensão abertos ao público, conforme a disponibilidade da instituição. Os mesmos são gratuitos, caso os participantes não queiram receber o certificado de conclusão, caso queiram, uma pequena taxa é cobrada (FAMATh, Núcleo de Pós-Gradu- 
ação, Extensão e Atividades Comunitárias, 2007), fato semelhante ao ocorrido na UNESA.

A Escola Superior de Ensino Helena Antipoff está vinculada à Sociedade Pestalozzi do Estado do Rio de Janeiro e atua em Niterói desde 1984. A Sociedade Pestalozzi foi fundada no Brasil no ano de 1932, em Belo Horizonte, Minas Gerais, por Helena Antipoff, responsável pela implantação, no país, de uma política de educação e assistência à criança portadora de deficiência. Foi esta educadora que iniciou o Movimento Pestalozziano no Brasil, que atualmente conta com mais de cem instituições espalhadas por todo o país.

A Sociedade Pestalozzi do Estado do Rio de Janeiro (SPERJ) foi fundada em 1948. Três ações distintas e complementares definiram a vocação da SPERJ: a assistência médico-social, a assistência educacional aos portadores de deficiência e a formação de recursos humanos.

Desde as suas origens, portanto, a SPERJ aliou, na sua proposta de trabalho, o binômio Saúde-Educação, ao mesmo tempo em que se preocupava com a formação de pessoal especializado para a realização de suas finalidades. É por estas razões que mantém dois centros educacionais em sua sede, ambos em homenagem à sua fundadora: o Centro Experimental Helena Antipoff - CEHA e a Escola Superior de Ensino Helena Antipoff - ESEHA (ASSOCIAÇÃO PESTALOZZI DE NITERÓI, 2006 e 2007).

O Centro Experimental Helena Antipoff (CEHA) contribui com uma proposta inclusiva. Ele educa crianças na sua unidade de educação básica - a Escola - e profissionaliza jovens no seu Centro de Educação Profissional, além de formar técnicos de Enfermagem através da sua unidade de Educação Profissional Técnica. A escola funciona como Escola Inclusiva, atendendo a 145 alunos com idade de 3 a 16 anos, distribuídos em dois turnos, em turmas de 10 alunos, no máximo, nos níveis de Educação Infantil e Ensino Fundamental seriado e não-seriado. Os alunos contam com atendimento médico e terapêutico gratuito adequado às suas necessidades.

Atualmente, a ESEHAé mais conhecida como "Faculdades Pestalozzi". Foi credenciada pelo MEC em 1984 e a sua sede localiza-se no bairro de Pendotiba, havendo uma unidade também no centro de Niterói. É uma instituição particular em sentido estrito, mantida pela Associação Pestalozzi de Niterói-RJ, pessoa jurídica de direito privado.

A ESEHA possui 128 docentes, sendo 03 doutores, 47 mestres, 78 especialistas. É constituída atualmente de 36 funcionários técnico-administrativos (VAZ, 2007). Possui 890 alunos matriculados nos seus cursos de graduação (MEC. INEP, 2007). 
O curso de graduação mais procurado nesta instituição é o de Fisioterapia (574 alunos matriculados), seguido dos cursos de Fonoaudiologia e Odontologia (83 alunos) (MEC. INEP, 2007).

No âmbito da pós-graduação lato sensu, são oferecidos vários cursos nas áreas de Fisioterapia; Fonoaudiologia; Psicologia; Arte e Cultura; Saúde, Educação e Reabilitação; Odontologia; Meio-Ambiente, dentre outras, sendo a maior parte da área de Fisioterapia (ASSOCIAÇÃO PESTALOZZI DE NITERÓI, 2006 E 2007).

No que se refere à extensão, além dos inúmeros cursos oferecidos, em diversas áreas, destacamos:

\section{a) Centro de Reabilitação Geral}

Atendendo a uma demanda de atenção multidisciplinar de pacientes de todas as idades, provenientes, em sua maioria, do Sistema Único de Saúde (SUS), os serviços de reabilitação são disponibilizados à comunidade em geral e, em especial, aos alunos da Escola (CEHA), sob forma individual ou de grupo, em três grandes modalidades - Fisioterapia, Fonoaudiologia e Terapia Ocupacional - além do suporte da Psicologia e do Serviço Social. Como parte do Centro de Reabilitação Geral, existe, desde setembro de 2001, o Centro de Convivência de Idosos Alberto Torres, conhecido como Casa Rosa, num espaço de convivência integrada que se desenvolveu a partir do Programa de Atenção à Terceira Idade, em funcionamento desde 1997. Lá, os idosos, principalmente os portadores de necessidades especiais, têm atendimento terapêutico em grupo ou individual, e participam de oficinas terapêuticas (culinária, horta, jardinagem, atividades ocupacionais).

b) Centro de Orientação Infanto-Juvenil - COIJOC

Articulado à unidade de Educação Básica, o Centro de Orientação InfantoJuvenil desenvolveu estratégias que otimizaram o atendimento de 122 jovens das escolas da comunidade com dificuldades de aprendizagem, dando-lhes orientação e apoio através de uma equipe multidisciplinar composta de profissionais, voluntários e estagiários. Em 2002, o Programa Parcerias foi ampliado com a participação de 40 escolas. Como uma das metas principais do COIJOC, destaca-se o Projeto Para que essa rua seja nossa, para pacientes de 7 a 16 anos com dificuldades de aprendizagem. Outras metas são a implantação do Programa de Recuperação Paralela e do Programa de Alfabetização de Adultos.

c) Programa de Atendimento a Autistas e Psicóticos - PAPs

Criado em 1997 como projeto, o PAPs tornou-se um programa bem sucedido, atendendo a uma demanda de crianças e adolescentes, de 3 a 14 anos, que 
apresentam sintomatologia dentro da esfera neuropsiquiátrica, notadamente a Síndrome do Autismo. O perfil do serviço é menos médico e mais psicoeducacional, sem desconsiderar o apoio de profissionais de saúde mental. Com muitas parcerias externas e internas, o programa insiste num modelo em que a família é o agente prioritário do processo, tendo sido criada uma ONG - a Associação de Pais dos Autistas de Niterói - em decorrência do trabalho (ASSOCIAÇÃO PESTALOZZI DE NITERÓI, 2006 e 2007).

O Conservatório de Música de Niterói foi fundado em 1914, no Teatro João Caetano, durante a Assembléia Geral da Sociedade Symphonica Fluminense, com a finalidade de ampliar a área de educação artística - ensinando música, promovendo recitais e audições e tudo mais que se relacionasse à divulgação da arte. O Conservatório foi o primeiro estabelecimento de ensino da música no território fluminense. Em 12 de abril de 1965, por ato do Presidente da República, foi elevado à categoria de escola de nível superior. Nesse mesmo ano, a Prof ${ }^{a}$ Raymunda Vianna Magalhães firmou um convênio no dia 22 de dezembro com a Universidade Federal Fluminense, que durou até 1975, terminando por motivos políticos. Mas o Conservatório de Música de Niterói continuou mantendo seus cursos superiores até os dias atuais e tem, hoje, a projeção das grandes escolas formadoras no Brasil, sendo uma instituição privada filantrópica (CONSERVATÓRIO DE MÚSICA DE NITERÓI, 2007).

Localizado no centro da cidade de Niterói, possui 22 professores, 1 doutor, 5 mestres, 7 especialistas e 9 graduados, sendo o seu corpo discente hoje constituído de 21 alunos (OLIVEIRA, 2007).

O Conservatório de Música de Niterói oferece os seguintes cursos superiores de graduação: Educação Artística, habilitação Música (Licenciatura); e Música, habilitações Canto (Bacharelado), Composição (Bacharelado), Piano (Bacharelado), Regência (Bacharelado), Violão (Bacharelado), Clarineta (Bacharelado), Flauta (Bacharelado), Trompete (Bacharelado), Violino (Bacharelado), todos reconhecidos pelo MEC (VIANNA, 2007).

Dos 6 Seminários Teológicos analisados, 5 são de orientação Batista / Evangélica, oferecendo cursos superiores de Teologia e formando líderes e pastores para as igrejas batistas e evangélicas de Niterói. Apenas o Seminário São José é de orientação católica, oferecendo cursos de Filosofia e Teologia, voltados, sobretudo, para a formação de seminaristas da Arquidiocese de Niterói. A supremacia dos Seminários Teológicos Batistas de orientação evangélica pode ser associada à proliferação de Igrejas Evangélicas pelo país, e particularmente, em Niterói, e a sua necessidade de catequizar os pastores e o rebanho como um todo na direção das suas crenças religiosas. 


\section{Considerações finais}

Consideramos que Niterói seja uma cidade universitária por excelência, pois com apenas $131,8 \mathrm{Km} 2$ e 471.403 habitantes, possui 16 instituições que oferecem ensino superior interagindo ativamente com a cidade.

AUniversidade Federal Fluminense ocupa, sem dúvida, um lugar de destaque no município, no que se refere ao ensino, à pesquisa e à extensão, sobressaindose no âmbito da pós-graduação stricto sensu e da pesquisa, em todas as áreas do conhecimento. As instituições privadas existentes em Niterói voltam-se mais para o ensino de graduação e de pós-graduação lato sensu, oferecendo também projetos, cursos e serviços de extensão relevantes para o município.

Em geral, a oferta dos cursos de graduação e de pós-graduação acompanha a demanda dos estudantes e do mercado, sobretudo no que se refere às instituições particulares. Os cursos mais procurados são os que possuem mais tradição, maior prestígio social e melhores possibilidades de empregos bem remunerados, tais como Medicina, Direito, Administração. A elevada procura pelo curso depende, também, das características da instituição, como por exemplo, no caso das Faculdades Integradas Maria Thereza há grande procura pelos cursos de Psicologia e de Ciências Biológicas, áreas com forte tradição nas FAMATh; assim como a forte demanda pelos cursos de Fisioterapia e Fonoaudiologia na Escola Superior de Ensino Helena Antipoff está associada às suas características específicas voltadas para portadores de necessidades especiais.

Cursos como Comunicação Social, Educação Física e Engenharia de Petróleo têm sido muito procurados pelos estudantes. No caso da Comunicação Social, isto se deve à grande valorização dos meios de comunicação, da publicidade, da propaganda e marketing, na contemporaneidade, numa sociedade de consumo guiada pela mídia. A demanda pelo curso de Educação Física pode ser interpretada à luz do cultivo de um corpo belo e saudável, pois a estética corporal também é muito valorizada em nossa sociedade atual, abrindo múltiplas possibilidades de trabalho na área. No caso dos cursos de Engenharia de Petróleo e Gás, a alta demanda deve-se à expansão do setor de Petróleo no município de Niterói e na região fluminense como um todo.

Uma tendência geral verificada nas instituições foi a de que os cursos mais caros são os que têm mais prestígio social, oferecem melhores possibilidades de remuneração no mercado de trabalho, pelo menos no imaginário da sociedade, sendo mais procurados pelos estudantes.

Os cursos menos procurados pelos alunos são os que possuem menor status social, sendo menos valorizados no mercado de trabalho. Como exemplos, 
podemos citar os cursos de formação de professores, que possuem preços mais modestos.

Neste sentido, há uma divisão dos cursos, no campo universitário, por tradição, prestígio social, possibilidade de emprego rentável no mercado de trabalho, custo, sendo que os estudantes de maior poder aquisitivo, que possuem também maior capital cultural e social direcionam-se para os cursos mais valorizados socialmente, enquanto que os alunos com menor poder aquisitivo, menor acúmulo de capital social e cultural vão, em geral, para os cursos menos valorizados, reforçando, com isto, as desigualdades sociais e a hierarquia social no campo das profissões.

Há que se ressaltar que a pós-graduação lato sensu tornou-se um terreno propício para o lucro nas instituições de educação superior, sendo oferecidos cursos os mais variados, para todos os bolsos. Neste sentido, mesmo na UFF, uma universidade pública federal, estes cursos têm sido cobrados dos estudantes e já foi institucionalizada e banalizada a privatização por dentro da instituição, via cursos denominados de auto-financiáveis, mas na verdade pagos pelos estudantes.

Apesar das suas contradições, na "cidade universitária" de Niterói, as instituições de ensino superior assumem um papel social de extrema relevância, configurando-se como locais importantes de formação de uma juventude que deposita nelas o sonho de uma vida melhor.

\section{Referências}

ASSOCIAÇÃO PESTALOZZI DE NITERÓI. Dados sobre a instituição. Disponível em: <http:// www.pestalozzi.org.br>. Acesso em: 23 set. 2006; 13 fev. 2007.

ASSUMPÇÃO, Juarez de Oliveira (Coordenador Acadêmico da UCAM). Dados sobre a instituição. Entrevistador Diego Jorge Fereira. Niterói, 08 ago 2006.

BASTOS, Elayne (Assessora de Aloysio Loyola, Coordenador da FGV-Capital Humano, Tecnologia e Treinamento Ltda em Niterói). Dados sobre a instituição obtidos via e-mail. Niterói, 19 maio 2007.

BRAGA, Marcos Moreira (Diretor Acadêmico das FAMATh). Dados sobre a instituição. Entrevistador Fernando de Souza Paiva. Niterói, 20 jul. 2006. 
BERLIN, Lilyan Guimarães (Coordenadora de Cursos Seqüenciais da UCAM). Dados sobre a instituição. Entrevistador Diego Jorge Ferreira. Niterói, 05 dez. 2006.

CENTRO UNIVERSITÁRIO PLÍNIO LEITE. Apresentação. Disponível em: $<$ http://www.unipli.com.br/siteunipli/unipli_001.htm>. Acesso em: 07 maio $2007 \mathrm{a}$.

CENTRO UNIVERSITÁRIO PLÍNIO LEITE. Pós-Graduação. Disponível em: $<$ http://www.unipli.com.br/siteunipli/pos_002.htm>. Acesso em: 07 maio $2007 b$.

CONSERVATÓRIO DE MÚSICA DE NITERÓI. Dados sobre a Instituição. Disponível em: <http://www.conservatoriocmn.com.br>. Acesso em: 19 ago. 2007.

ESCOLA SUPERIOR DE ENSINO HELENA ANTIPOFF. MEC/INEP, Cadastro das Instituições de Educação Superior. Disponível em: <http://www. educacaosuperior.inep.gov.br>. Acesso em: 20 mar. 2007.

FACULDADES INTEGRADAS MARIA THEREZA. História. Disponível em: <http://www.famath.com.br/webfamath/info/historia.aspx>. Acesso em: 22 maio 2006.

FACULDADES INTEGRADAS MARIA THEREZA. MEC/INEP, Cadastro das Instituições de Educação Superior. Disponível em: <http://www.educacaosuperior.inep.gov.br/funcional/listas_ies.asp >. Acesso em: 10 abr. 2007.

FACULDADES INTEGRADAS MARIA THEREZA. Núcleo de Pós-Graduação, Extensão e Atividades Comunitárias. Acesso às informações em 30 mar. 2007.

FUNDAÇÃO GETÚLIO VARGAS, Núcleo Niterói, Capital Humano. Dados sobre a instituição. Disponível em: <http://www.capital-h.com.br./> Acesso em: 14 maio 2007.

INSTITUTOS SUPERIORES LA SALLE. Dados sobre a instituição. Disponível em: <http://www.unilasalle.org/> Acesso em: 10 abr. 2007.

INSTITUTOS SUPERIORES LA SALLE. MEC/INEP, Cadastro das instituições de educação superior. Disponível em: <http://www.inep.gov.br/> Acesso em: 20 abr. 2007. 
MONCLAR, Carlos Alberto Medeiros (Coordenador de Cursos Politécnicos da UCAM). Dados sobre a instituição. Entrevistador Diego Jorge Ferreira. Niterói, 15 dez. 2006.

NITERÓI. Prefeitura de Niterói. Prazer de viver aqui. Disponível em: $<$ http:// www.niteroi.rj.gov.br>. Acesso em: 30 maio 2007.

OLIVEIRA, Rita de Cássia de (Secretária do Conservatório de Música de Niterói). Dados sobre a instituição. Entrevistador Emiliano Côrtes Barbosa. Niterói, 20 ago 2007.

PAULA, Maria de Fátima e AZEVEDO, Marcela Davino. Políticas e práticas de privatização do público na universidade: o caso UFF. Avaliação, Campinas, v. 11, n. 3, p. 91-111, set. 2006.

SILVA, Turíbio Tinoco da (Professor e Subcoordenador dos cursos de Ciências Biológicas e Biologia Marinha das FAMATh). Dados sobre a instituição. Entrevistador: Fernando de Souza Paiva. Niterói, 30 mar. 2007.

SOUZA, Bianca Antunes de. (Assessora de Comunicação e Marketing, UNILASALLE - RJ). Dados sobre a instituição. Entrevistadoras Izabel Cristina Mendel Souza e Simone de Abreu Duarte. Niterói, 20 mar. 2007.

SOUZA, Jurésia Mendonça de (Coordenadoria de Planejamento e Desenvolvimento Institucional do UNIPLI). Dados sobre a instituição. Entrevistadora Maria das Graças Gonçalves Machado Sales. Niterói, 23 abr. 2007.

UNIVERSIDADE CÂNDIDO MENDES. Histórico. Disponível em: <http:// www.ucam.edu.br/institucional/programas.asp>. Acesso em: 12 dez. 2006.

UNIVERSIDADE CÂNDIDO MENDES. Instituto a Vez do Mestre. Disponível em: <http://www.vezdomestre.com.br>. Acesso em: 24 nov. 2006.

UNIVERSIDADE CÂNDIDO MENDES. MEC/INEP, Cadastro das Instituições de Educação Superior. Disponível em: $<$ http://www.educacaosuperior.inep.gov. br>. Acesso em 30 abr. 2007.

UNIVERSIDADE ESTÁCIO DE SÁ. Dados sobre a instituição. Disponível em: $<$ http://www.estacio.br $>$. Acesso em: 02 maio 2007a.

UNIVERSIDADE ESTÁCIO DE SÁ. Dados sobre a instituição. Disponível em: <http://www.estacio.br/ferias/>. Acesso em 09 jul. 2007 b. 
UNIVERSIDADE ESTÁCIO DE SÁ. MEC/INEP, Cadastro das Instituições de Educação Superior. Disponível em: <http://www.educacaosuperior.inep. gov.br/funcional/listas_ies.asp>. Acesso em: 10 abr. 2007.

UNIVERSIDADE FEDERAL FLUMINENSE. Dados sobre a instituição. Disponível em: <http:// www.coseac.uff.br>. Acesso em: 19 abr.2007b.

UNIVERSIDADE FEDERAL FLUMINENSE, PROPLAN, Pró-Reitoria de Planejamento. Dados sobre a instituição. Disponível em: <http://webproplan. uff.br/catalogo/principa/numeros.htm>. Acesso em: 19 abr. 2007a.

UNIVERSIDADE SALGADO DE OLIVEIRA, UNIVERSO. Dados sobre a instituição. Disponível em: <http://www.universo.edu.br/>. Acesso em: 28 mar. 2007; 25 abr. 2007.

UNIVERSIDADE SALGADO DE OLIVEIRA, UNIVERSO. MEC/INEP, Cadastro das Instituições de Educação Superior. Disponível em: <http://www. educacaosuperior.inep.gov.br/funcional/info_ies_new.asp?pIES $=663>$. Acesso em: 20 maio 2007.

VAZ, Ana Cláudia Vieira. (Coordenadora de Recursos Humanos e Vice-Diretora da ESEHA). Dados sobre a instituição. Entrevistadora Maria de Fátima de Paula. Niterói, 30 abr. 2007.

VIANNA, Ruth (Diretora do Conservatório de Música de Niterói). Dados sobre a instituição. Entrevistador Emiliano Côrtes Barbosa. Niterói, 20 ago. 2007.

VIEIRA, José Ribas. A Universidade Federal Fluminense: de um projeto adiado à sua consolidação institucional - subsídios para uma interpretação. Niterói: $\mathrm{UFF} / \mathrm{PROAC}$, [s.d.]. 